\title{
Feto-maternal outcome in second versus first stage caesarean delivery in a tertiary medical care centre
}

\author{
Nupur Gupta, Taru Gupta*, Ritu Singh
}

Department of Obstetrics and Gynecology, ESI PGIMSR, Basaidarapur, New Delhi, Delhi, India

Received: 06 October 2018

Accepted: 27 October 2018

\section{*Correspondence:}

Dr. Taru Gupta,

E-mail: tarugupta1971@yahoo.com

Copyright: (C) the author(s), publisher and licensee Medip Academy. This is an open-access article distributed under the terms of the Creative Commons Attribution Non-Commercial License, which permits unrestricted non-commercial use, distribution, and reproduction in any medium, provided the original work is properly cited.

\begin{abstract}
Background: The aim is to study neonatal and maternal outcomes of the caesarean sections performed in first stage versus second stage of labour.

Methods: The retrospective analysis of data were done of caesarean section done at Department of Obstetrics and Gynaecology at ESI PGIMSR Basaidarapur New Delhi between January 2016 to December 2016. 45 women, who underwent second stage caesarean section were studied. For each case, two consecutive cases, who underwent caesarean delivery during the first stage of labour were taken as control for the study. Primary maternal outcomes of interest were uterine atonia, transfusion requirement, urinary system injury and postoperative complications.

Results: Out of 4477 deliveries, 1466 had caesarean section with a rate of 32\%. The rate of second stage caesarean section was $3 \%$ of total caesarean section and $1 \%$ of total deliveries. Second stage caesarean section had higher maternal and perinatal morbidity like atonic PPH (33.3\%), lower uterine segment extension (7\%), febrile morbidity (10\%), and need for blood transfusion (15\%). There were $15.5 \%$ NICU admission in second stage caesarean group while none in first stage group.

Conclusions: Caesarean section in the second stage of the labour is associated with increased maternal and neonatal morbidities. Special attention is required to the patients undergoing caesarean section in the second stage of the labour. They should be handled by senior and experienced obstetrician. Neonatologist should be present for every second stage caesarean section.
\end{abstract}

Keywords: Caesarean section, First stage of labour, Second stage labour

\section{INTRODUCTION}

Caesarean Section is the most commonly performed abdominal operation in women all over the world. Variable rates of caesarean section is reported between and within countries. ${ }^{1-3}$ The use of cesarean section (CS) has increased dramatically worldwide in the last decades. ${ }^{4}$ According to recent estimates, the average global rate of CS is $18.6 \%$, reaching $25 \%$ in the United Kingdom (UK) and more than $30 \%$ in The United States (US). ${ }^{4} \mathrm{CS}$ in the second stage of labor has also increased in prevalence from 0.9 in 1993 up to $1.8 \%$ in 2008 in the UK. In Medical colleges and teaching hospitals in India the overall rate of caesarean deliveries is $24.4 \%$. One fourth of the primary caesarean section are reported to be performed in the second stage of labour and are more complicated compared to the ones performed in the first stage. 5

Recently decline in the use of instrumental delivery, a combination of lack of training and supervision for junior staff in second stage decision-making, a loss of technique associated with difficult-assisted delivery and concerns relating to maternal and neonatal morbidity with associated litigation related issues might have contributed to this disturbing second stage caesarean section trend. 
Caesarean section at full dilatation of cervix with an impacted fetal head can be technically difficult and associated with increased trauma to the lower uterine segment and adjacent structures as well as increased haemorrhage and infection. ${ }^{6}$

Neonatal mortality and morbidity due to hypoxia and fetal trauma remains to be one of the major issues regarding the caesarean section performed in the second stage of labour. ${ }^{7-9}$

This study was carried out to determine the maternal and neonatal outcome associated with cesarean delivery in the second stage of labour and compared it with outcome in women undergoing cesarean delivery in first stage of labour.

\section{METHODS}

The retrospective analysis of caesarean section at Department of Obstetrics and Gynaecology at ESI PGIMSR Basaidarapur New Delhi between January 2016 to December 2016 was done. Ethical approval was obtained from institutional ethical committee.

This study compared caesarean sections done in the second stage of labour with caesarean sections in the first stage of labour. 45 women, who underwent second stage caesarean section were studied.

For each case, two consecutive cases, who underwent caesarean delivery during the first stage of labour were taken as control for the study.

\section{Inclusion criteria}

- Women with singleton fetus with vertex presentation and gestational age older than 37 weeks of gestation.

\section{Exclusion criteria}

- Women with maternal co-morbid disease and associated obstetric complications such as preeclampsia and diabetes mellitus.

- Women with major fetal structural or chromosomal abnormalities and pregnancies with placenta previa, malpresentations and abruption placentae.

The primary outcome was defined as estimated blood loss $>1000 \mathrm{ml}$. Secondary outcome included unintentional uterine incision extension, bladder or ureter iatrogenic damage, need for blood transfusion and postoperative presence of fever or wound infection. We also studied Apgar score at 5 minutes and need for NICU admission for the baby.

Maternal age, BMI, gestational age, augmentation of labour with oxytocin were recorded. Information was collected in structured format and included demographic data, relevant obstetric data, and indications for cesarean section, maternal and neonatal complications.

Statistical analysis was performed on SPSS software. Differences in the outcome, frequencies were analyzed using mean and Standard deviation and $\mathrm{P}$ values of less than 0.05 were accepted as indicating statistical significance.

\section{RESULTS}

During the study period, there were 4477 deliveries, with 1466 had caesarean deliveries with a rate of $32 \%$. There were 45 second stage caesarean sections. The rate of second stage caesarean section was $3 \%$ of total caesarean section and $1 \%$ of total deliveries. Deep transverse arrest (50 \%) and Obstructed labour $(25 \%)$ were the most common indications for the caesarean section in the second stage. Fetal distress $(40 \%)$ and failed induction $(40 \%)$ were the most common indications in the first stage caesarean sections.

Table 1 and Table 2shows among 45 patients, 36 (80\%) were primigravida and $9(20 \%)$ were multigravida in second stage caesarean section while in first stage caesarean section only $52 \%$ were primigravida. This shows that proper pelvic assessment at labour is necessary to avoid second stage caesarean section.

Table 1: Age data of mother in both groups.

\begin{tabular}{|llll|}
\hline $\begin{array}{l}\text { Age } \\
\text { (years) }\end{array}$ & $\begin{array}{l}\text { Second stage } \\
\text { Caesarean } \mathbf{n = 4 5}\end{array}$ & $\begin{array}{l}\text { First stage } \\
\text { Caesarean } \mathbf{n = 9 0}\end{array}$ & P value \\
\hline Under 20 & 3 & 9 & 0.458 \\
\hline $21-30$ & $39(86.6 \%)$ & $70(77.7 \%)$ & \\
\hline $31-40$ & 3 & 11 & \\
\hline
\end{tabular}

Table 2: Parity data of mother in both groups.

\begin{tabular}{|ll|ll|}
\hline Parity & $\begin{array}{l}\text { Second stage } \\
\text { Caesarean } \mathbf{n = 4 5}\end{array}$ & $\begin{array}{l}\text { First stage } \\
\text { Caesarean } \mathbf{n = 9 0}\end{array}$ & P value \\
\hline Primi & $36(80 \%)$ & $52(57.7 \%)$ & 0.018 \\
\hline Multi & $9(20 \%)$ & $38(42.2)$ & \\
\hline
\end{tabular}

Table 3 shows intra-operative findings and complications of caesarean section in second and first stage of labour. Fifteen $(33.3 \%)$ of the women undergoing caesarean section in the second stage of labour had PPH as compared to nine (10\%) women who underwent caesarean section in the first stage of labour.

Atonia and other causes of haemorrhage resulted in a significantly higher blood transfusion requirement in women undergoing caesarean section in the second stage of labour (33.3 vs $10 \%, \mathrm{P}<0.05)$. Lower uterine segment tear including extension and blood-stained urine were present in $15.5 \%$ of second stage caesarean section compared to $4 \%$ of first stage caesarean section. 
Table 3: Maternal complications.

\begin{tabular}{|c|c|c|c|}
\hline Maternal Complications & Second stage & First stage & $P$ value \\
\hline \multicolumn{4}{|c|}{ Caesarean $N=45$} \\
\hline PPH & $15(33.3 \%)$ & $9(10 \%)$ & 0.002 \\
\hline & \multicolumn{3}{|c|}{ All managed medically } \\
\hline LUS tear including extensions & $7(15.5 \%)$ & $4(4.4 \%)$ & 0.042 \\
\hline Blood stained urine & $7(15.5 \%)$ & $3(3.3 \%)$ & 0.016 \\
\hline Blood transfusion & $15(33.3 \%)$ & $9(10 \%)$ & 0.002 \\
\hline Febrile morbidity with wound sepsis & $10(22.2 \%)$ & $3(3.3 \%)$ & 0.0001 \\
\hline
\end{tabular}

Table 4 shows neonatal complications. APGAR Score $\leq 7$ at 5 minutes was more frequent $(11 \%)$ in the neonates of the mothers operated in the second stage of labour compared to the women operated in the first stage of labour (2.2\%).

Seven of the neonates $(15.5 \%)$ who were born to mothers underwent caesarean section of the second stage of labour were admitted to the neonatal intensive care unit (NICU) compared to none of the newborns born to mothers who underwent caesarean section in the first stage of the labour and the results were statistically significant $(\mathrm{P}<0.05)$.

Table 4: Neonatal complications.

\begin{tabular}{|llll|}
\hline Neonatal & $\begin{array}{l}\text { Second } \\
\text { stage } \\
\text { Caesarean } \\
\mathbf{N = 4 5}\end{array}$ & $\begin{array}{l}\text { First } \\
\text { stage }\end{array}$ & $\begin{array}{l}\text { Caesarean } \\
\mathbf{N}=\mathbf{9 0}\end{array}$ \\
\hline $\begin{array}{l}\text { Complications } \\
\text { 5 min APGAR } \\
\text { score }(<7)\end{array}$ & $5(11.1 \%)$ & $2(2.2 \%)$ & 0.041 \\
\hline $\begin{array}{l}\text { NICU } \\
\text { admissions }\end{array}$ & $7(15.5 \%)$ & - & 0.0003 \\
\hline
\end{tabular}

\section{DISCUSSION}

This was retrospective study conducted at ESI PGISR Basaidarapur from January 2016 to December 2016. Out of 1466 caesarean sections 45 were performed in the second stage of labour which contributes to $1 \%$ of the total deliveries and 3\% of the caesarean sections. Deep transverse arrest was the most common indication (50\%) for caesarean section in second stage of labor.

The study conducted by Jonna Malathi and Venigalla Sunita had the rate of second stage cesarean section $4.1 \%$. Their study had deep transverse arrest as the second most common indication (22\%) for caesarean section. ${ }^{10}$ Study conducted by Prameela showed deep transverse arrest was present in $61 \%$ cases and was the most common indication as in present study. ${ }^{11}$ In a study by Jyoti Jayaram also showed deep transverse arrest was the most common indication $(38.46 \%) .{ }^{12}$ The present study showed that the caesarean section performed in the second stage of labour have significantly higher maternal and neonatal morbidity. Allen et al had compared the maternal and neonatal morbidity of the caesarean section in the first and second stage of labour in a similar study. ${ }^{13}$ The increased maternal morbidity can be explained due to the difficulty in handling the fetus impacted to the maternal pelvis.

Development of uterine atonia and requirement of uterine or hypogastric artery ligation in the case of severe haemorrhage are also found to be more frequent in caesarean section performed in the second stage of labour and can be due to the longer labour resulting in uterine fatigue. The unfavorable neonatal outcomes are probably due to prolonged labour which leads to hypoxia. Present study also showed that there are increased operative complications in second stage section like increased risk of uterine angle extension, post-partum haemorrhage, need for blood transfusion when compared with first stage section and was statistically significant, similar to a study done by Swapan das et al.

In another study by Asicioglu et al, they observed that Caesarean deliveries performed in the second stage were associated with increased intraoperative complications, unintended extensions, need for blood transfusion, higher rates of endometritis and requirement for hysterectomy and were, therefore, associated with longer operation time and hospital stay. ${ }^{14,15}$ Neonatal complications included a significantly low Apgar score at 5 minutes, increased neonatal death, admission to the neonatal intensive care unit, septicaemia and fetal injury (all p < 0.05) Cebekulu and Buchmann in South Africa randomised 39 patients undergoing caesarean section in the first stage of the labour and 39 in the second stage of the labour and have also concluded that caesarean section in the second stage of the labour causes more maternal and neonatal morbidity. ${ }^{16}$ Similar results were shown by Sucak et al. ${ }^{17}$

There are controversies regarding the fetal outcome of the CS performed in the second stage of labour, while some previous studies fail to demonstrate an increased fetal complication rate. ${ }^{8,14,16,17}$ In contrast to some other studies including the current study, the risk of CS in the second stage of labour is not confined to the mother and has adverse prognostic impact on fetal outcome as well. ${ }^{9,10,12}$ 
In a systemic review and a meta-analysis it was shown that ten studies were finally retrieved involving 23,104 singleton childbearing women $(18,160$ operated in the first stage and 4944 in the second stage of labour). ${ }^{18}$ Second stage caesarean section seems to lead to higher maternal admissions to ICU (OR 7.41, 95\% CI 2.4722.5) and higher transfusion rates (OR 2.60, 95\% CI 1.49-2.54). Neonatal death rates were also increased (OR 5.20 , 95\% CI 2.49-10.85) along with admissions to neonatal unit (OR 1.63, 95\% CI 0.91-2.91) and rates of Apgar score less than 7 in 5minute (OR 2.77, 95\% CI 1.02-7.50).

\section{CONCLUSION}

In conclusion present study suggests that women undergoing caesarean section in the second stage of labour have increased maternal and fetal morbidity and therefore require a special care and should be handled and operated by experienced obstetricians. The neonatologists should be present in every case of caesarean section performed in the second stage of labour. The rate of complications could have been avoided by improvement of antenatal care, pelvic assessment in early labour by experienced obstetricians, by use of partogram for monitoring of labour and timely intervention. Second stage section should be done by experienced obstetricians.

\section{Funding: No funding sources}

Conflict of interest: None declared

Ethical approval: The study was approved by the Institutional Ethics Committee

\section{REFERENCES}

1. Dumont A, De Bernis L, Bouvier-olle MH, Bréart G, Caesarean section rate for maternal indication in subSaharan Africa: a systematic review. The Lancet. 2001;358(9290):1328-33

2. Murray SF. Health sector reform and rise of caesarean birth in Chile. Lancet. 1997;349(9044):64.

3. Vitner D, Bleicher I, Levy E, Sloma R, Kadour-Peero $\mathrm{E}$, et al. Differences in outcomes between cesarean section in the second versus the first stages of labor. J Maternal-Fetal Neon Med. 2018:1-4.

4. Betrán AP, Ye J, Moller AB, Zhang J, Gülmezoglu $\mathrm{AM}$, Torloni MR. The increasing trend in caesarean section rates: global, regional and national estimates: 1990-2014. PloS one. 2016;11(2):e0148343.

5. Gifford DS, Morton SC, Fiske M, Keesey J, Keeler E, Kahn KL. Lack of progress in labor as a reason for cesarean. Obstet Gynecol. 2000;95(4):589-95.

6. Seal SL, Kamilya G, Mukherji J, Bhattacharyya SK, De A, Hazra A. Outcome in second-versus first-stage cesarean delivery in a teaching institution in eastern India. Am J Perinatol. 2010;27(06):507-12.

7. Fasubaa OB, Ezechi OC, Orji EO, Ogunniyi SO, Akindele ST, Loto OM,. Delivery of the impacted head of the fetus at caesarean section after prolonged obstructed labour: a randomised comparative study of two methods. J Obstet Gynaecol. 2002;22(4):375-8.

8. Winovitch KC, Wing DA, Lagrew DC, Chung JH. The risk of acute neonatal morbidities in the delivery room after primary cesarean at term: influence of labor and stage. Am J Perinatol. 2009;26(08):545-51.

9. Allen VM, O'connell CM, Baskett TF. Maternal and perinatal morbidity of caesarean delivery at full cervical dilatation compared with caesarean delivery in the first stage of labour. BJOG: Int J Obstet Gynaecol. 2005;112(7):986-90.

10. Malathi J, Sunita V. Comparison of obstetric outcome between first and second stage cesarean sections in rural tertiary hospital. Int J Pharm Biomed Res. 2012;3(4):222-5.

11. Prameela. Comparison of obstetric and neonatal outcome between first and second stage caesarean sections in Tertiary Hospital, MMC and RI, Mysore. Int J Recent Trends Sci Technol.2015;14(3):520-2

12. Jayaram J, Mahendra G, Vijayalakshmi S. Feto maternal Outcome in Cesarean Sections Done in Second Stage of Labor. Indian J Obstet Gynaecol Res 2016;3(1):51-4

13. Allen VM, O'connell CM, Baskett TF. Maternal and perinatal morbidity of caesarean delivery at full cervical dilatation compared with caesarean delivery in the first stage of labour. BJOG: An International J Obstet Gynaecol. 2005;112(7):986-90.

14. Das S, Sarkar SK. Fetomaternal outcome in second versus First stage caesarean delivery in a tertiary rural medical college. IOSR J Dent Med Sci. 2014;13(12):28-30.

15. Asicioglu O, Gungorduk K, Yildirim G, Asicioglu BB, Gungorduk OC, Ark C et al. Second- stage vs first stage caesarean delivery: Comparison of maternal and perinatal outcomes. J Obstet Gynecol. 2014;34(7):598604.

16. Cebekulu L, Buchmann EJ. Complications associated with cesarean section in the second stage of labor. Int $\mathbf{J}$ Gynecol Obstet. 2006;95(2):110-4.

17. Sucak A, Çelen Ş, Akbaba E, Soysal S, Moraloglu O, Danışman N. Comparison of nulliparas undergoing cesarean section in first and second stages of labour: a prospective study in a tertiary teaching hospital. Obstetrics and gynecology international. 2011;2011.

18. Pergialiotis V, Vlachos DG, Rodolakis A, Haidopoulos D, Thomakos N, Vlachos GD. First versus second stage C/S maternal and neonatal morbidity: a systematic review and meta-analysis. Europ J Obstet Gynecol Reprod Biol. 2014;175:15-24.

Cite this article as: Gupta N, Gupta T, Singh R. Feto-maternal outcome in second versus first stage caesarean delivery in a tertiary medical care centre. Int J Reprod Contracept Obstet Gynecol 2018:7:5084-7. 